University of Wollongong

Research Online

Faculty of Engineering and Information

Faculty of Engineering and Information

Sciences - Papers: Part B

Sciences

2020

\title{
Model Predictive Control for a New Magnetic Linked Multilevel Inverter to Integrate Solar Photovoltaic Systems with the Power Grids
}

\author{
A M. Mahfuz-Ur-Rahman \\ University of Wollongong, ammur786@uowmail.edu.au \\ Md Rabiul Islam \\ University of Wollongong, mrislam@uow.edu.au \\ Kashem M. Muttaqi \\ University of Wollongong, kashem@uow.edu.au \\ Danny Sutanto \\ University of Wollongong, soetanto@uow.edu.au
}

Follow this and additional works at: https://ro.uow.edu.au/eispapers1

Part of the Engineering Commons, and the Science and Technology Studies Commons 


\title{
Model Predictive Control for a New Magnetic Linked Multilevel Inverter to Integrate Solar Photovoltaic Systems with the Power Grids
}

\begin{abstract}
The multilevel inverters are becoming increasingly popular for use in the grid integration of wind and photovoltaic (PV) power plants due to their higher voltage handling capability and the better output power quality. There are several types of multilevel inverters that have been proposed in the literature; among them the active neutral point clamp (ANPC) multilevel inverters have been drawing significant attention specially for solving the problems with other multilevel inverters. However, with the increase of number of levels, the ANPC requires more electronic switches and flying capacitors, by which the complexity and the cost increases. In this paper, an ANPC inverter with a reduced number of switches and flying capacitors is presented for the grid integration of the solar PV systems controlled using the model predictive control technique. The proposed power converter effectively utilizes the dc bus voltage more when compared with the traditional ANPC converter. In the proposed inverter, a high frequency transformer is used to eliminate the voltage balancing problems faced by the traditional ANPC inverters. The proposed magnetic linked power converter provides the galvanic isolation, which is one of the most critical issues for traditional transformer-less grid connected PV systems. The proposed topology makes the control strategy simple and makes the power conversion system reliable for the photovoltaic power plants.
\end{abstract}

\section{Keywords}

predictive, control, magnetic, linked, multilevel, inverter, model, integrate, systems, solar, photovoltaic, power, grids

\section{Disciplines}

Engineering | Science and Technology Studies

\section{Publication Details}

A. M. Mahfuz-Ur-Rahman, M. Islam, K. M. Muttaqi \& D. Sutanto, "Model Predictive Control for a New Magnetic Linked Multilevel Inverter to Integrate Solar Photovoltaic Systems with the Power Grids," IEEE Transactions on Industry Applications, vol. Online First, 2020. 


\title{
Model Predictive Control for a New Magnetic Linked Multilevel Inverter to Integrate Solar Photovoltaic Systems with the Power Grids
}

\author{
A. M. Mahfuz-Ur-Rahman, Student Member, IEEE, Md. Rabiul Islam, Senior Member, IEEE, Kashem \\ M. Muttaqi, Senior Member, IEEE, Danny Sutanto, Senior Member, IEEE
}

\begin{abstract}
The multilevel inverters are becoming increasingly popular for use in the grid integration of wind and photovoltaic (PV) power plants due to their higher voltage handling capability and the better output power quality. There are several types of multilevel inverters that have been proposed in the literature; among them, the active neutral point clamp (ANPC) multilevel inverters have been drawing significant attention especially for solving the problems with other multilevel inverters. However, with the increase of the number of levels, the ANPC requires more electronic switches and flying capacitors, by which the complexity and the cost increases. In this paper, an ANPC inverter with a reduced number of switches and flying capacitors is presented for the grid integration of the solar PV systems controlled using the model predictive control technique. This model predictive control technique uses a discrete-time model of the system to predict the future value of the active power and the reactive power for seven identified voltage vectors and selects the vector for the operation which causes minimum cost function. The proposed power converter topology also effectively utilizes the de bus voltage more when compared with the traditional ANPC converter. In the proposed inverter, a high-frequency transformer is used to eliminate the voltage balancing problems faced by the traditional ANPC inverters. The proposed magnetic linked power converter provides galvanic isolation, which is one of the most critical issues for traditional transformer-less gridconnected PV systems. The proposed topology makes the control strategy simple and makes the power conversion system reliable for the photovoltaic power plants. The model predictive controlbased power converter topology is simulated in MATLAB/Simulink environment and also validated in the laboratory test platform.
\end{abstract}

Keywords- active neutral point clamp, switch number reduction, capacitor number reduction, multilevel inverter, grid integration, inverter loss analysis, solar photovoltaic, model predictive control.

\section{INTRODUCTION}

$\mathbf{P}$ HOTOVOLTAIC (PV) is one of the most rapidly growing renewable energy sources having the ability to reduce the

Manuscript received May 17, 2020; accepted 12 Sept. 2020. This work was supported by the Australian Renewable Energy Agency (ARENA). (Corresponding author: A. M. Mahfuz-Ur-Rahman.)

A. M. Mahfuz-Ur-Rahman, M. R. Islam, K. M. Muttaqi, and D. Sutanto are with the School of Electrical, Computer and Telecommunications Engineering, University of Wollongong, NSW 2522, Australia. (e-mail: ammur786@uowmail.edu.au, mrislam@uow.edu.au, rabiulbd@hotmail.com, kashem@uow.edu.au, soetanto@uow.edu.au.)

Color versions of one or more of the figures in this paper are available online at $\mathrm{http} / /$ ieeexplore.ieee.org.

Digital Object Identifier will be inserted here upon acceptance. world enormous challenges, such as climate change and fossil fuel depletion. Power electronic converters are the key elements that interconnect the PV power plants with the grid and provide the conditioning operation of the energy conversion [1], [2]. Traditionally, the two-level inverter-based solar power conversion systems are commonly used for the solar home systems and in large scale solar power conversion systems, where a line filter is used to reduce the harmonics at the output voltage and a power frequency transformer is used for isolation purpose and for stepping up the line voltage. But the use of the power frequency step-up transformers and the filter circuits can increase the total loss by about $50 \%$ and the system volume by about $40 \%$ [3].

A lot of research work has been devoted to developing novel power electronic converter topologies to interconnect the PV power plants with the electrical power grid efficiently. Recently, the design of multilevel inverter topologies has taken on an accelerated pace due to the requirement of high voltage handling capacity and improved power quality [4] [6]. The three main topologies of the multilevel inverters are: (i) the neutral point clamp, (ii) the flying capacitor and (iii) the cascaded H-bridge topologies [7].

The authors in [8], [9] have proposed other types of multilevel inverter topologies, such as the modular multilevel and the stacked multi cells topologies. Recently, the active neutral point clamp (ANPC) multilevel inverter topology [10] - [15] is becoming increasingly popular due to its ability to overcome the problems of the conventional multilevel inverter topologies. The ANPC multilevel inverter topology requires fewer clamping devices and flying capacitors than those required in the basic multilevel inverters.

However, with the increase of the number of levels, there is a significant increase in the number of the power electronic switches and the auxiliary flying capacitors required in the ANPC converter topology. These extra components and devices increase the converter size, cost and control complexity of the flying capacitors [16]. Moreover, the increased number of capacitors makes the conversion system bulky and reduces the lifetime of the converters. Reference [14] proposes a reduced switch ANPC for the grid integration of PV plants. However, this topology requires extra control for balancing the voltage across the capacitors. Moreover, this topology utilizes a power frequency transformer which ultimately makes the system bulky.

In this paper, a novel ANPC multilevel inverter topology is 
presented, which not only utilizes a smaller number of switching devices and auxiliary flying capacitors but also generates a balanced isolated dc power supply using the highfrequency magnetic link for the ANPC. Also, the proposed topology eliminates the extra control required for the capacitor voltage balancing and the need for power frequency transformer. Moreover, the proposed ANPC multilevel inverter topology allows $100 \%$ of the dc bus voltage to be utilized, when compared to that of the traditional ANPC multilevel inverter topology, which can only utilize up to $50 \%$ of the dc bus voltage. Further, the proposed magnetic linked ANPC multilevel inverter also provides galvanic isolation to the grid-connected PV system.

The main contributions of this paper are:

- The paper implements the model predictive control technique for the control of a new power converter topology;

- The proposed converter has reduced number of switches and capacitors;

- The proposed converter can utilize $100 \%$ of the dc bus voltage;

- The proposed converter can solve the capacitor voltage balancing issue with the use of the proposed high-frequency magnetic link.

- The proposed converter provides galvanic isolation to the grid-connected PV system

\section{TRAditional MUlTiLEVEL INVERTERS}

The main conventional multilevel inverter topologies are the cascaded H-bridge multilevel, the neutral point clamp multilevel and the flying-capacitor multilevel topologies. As the number of levels increases in the multilevel inverter topologies, the number of devices increases significantly.

A nine-level single-phase cascaded H-bridge multilevel inverter topology requires $4 \mathrm{dc}$ power sources and 16 switching devices [7]. Here, a single H-bridge unit can develop three voltage levels $+\mathrm{Vdc},-\mathrm{Vdc}$ and 0 . Thus by

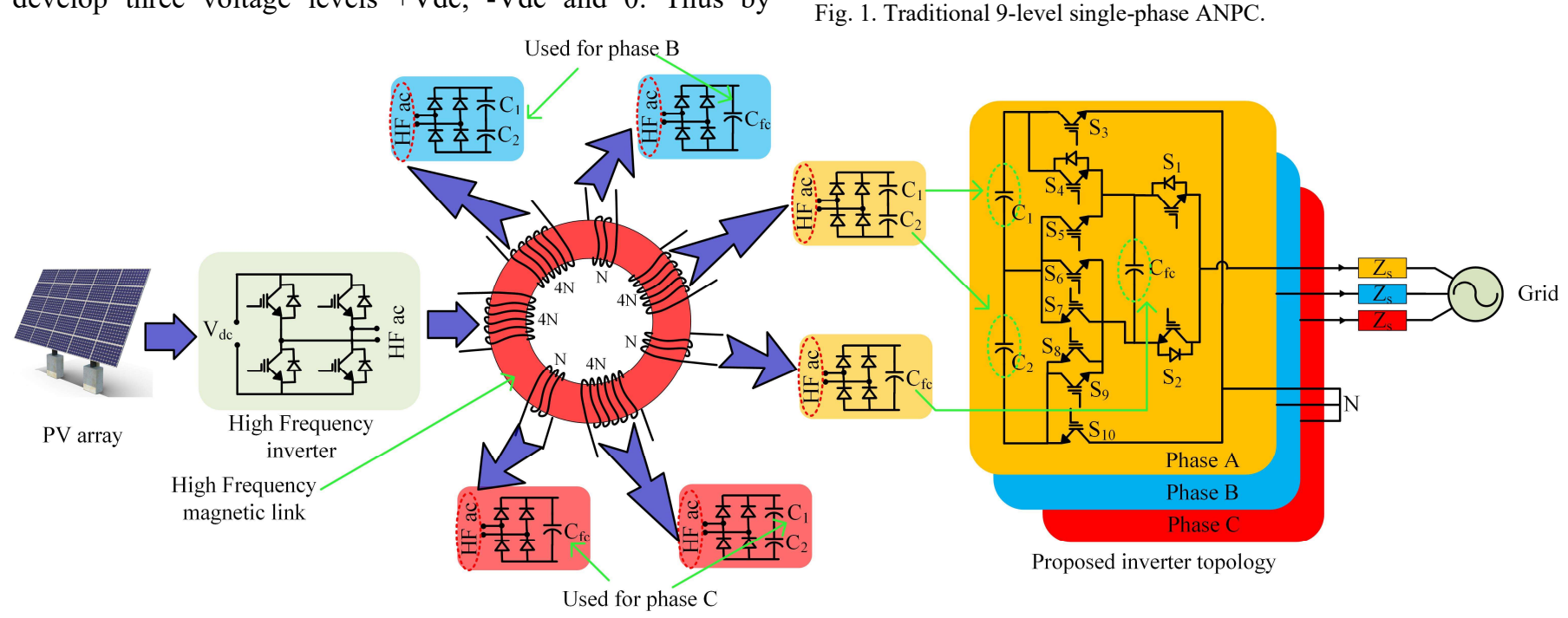

cascading several H-bridges, a higher output voltage can be obtained.

A nine-level single-phase neutral point clamp multilevel inverter topology requires 16 switching devices, 14 diodes, 8 dc-link capacitors and $1 \mathrm{dc}$ power source [7]. In general, this topology requires $1 \mathrm{dc}$ power source, $(\mathrm{m}-1)$ dc-link capacitors, $(2 \mathrm{~m}-2)$ switching devices and $(2 \mathrm{~m}-4)$ clamping diodes to develop a single-phase m-level inverter. One of the major drawbacks of this topology is the utilization of the dc bus voltage. It can only utilize up to $50 \%$ of the dc bus voltage.

A nine-level single-phase flying capacitor multilevel inverter topology requires $1 \mathrm{dc}$ power source, 16 switching devices, 2 dc-link capacitors and 7 flying capacitors [7]. In general, this topology requires $1 \mathrm{dc}$ power source, $2 \mathrm{dc}$-link capacitors, and (m-2) flying capacitors. This topology can also only utilize the same $50 \%$ dc bus.

As the voltage levels are increased, not only the number of the clamping diodes and dc-link capacitors in the neutral point clamp inverter and the flying capacitors multilevel inverter topology increases, but the difficulty in ensuring that the voltages across the dc-link capacitors are balance increases tremendously.

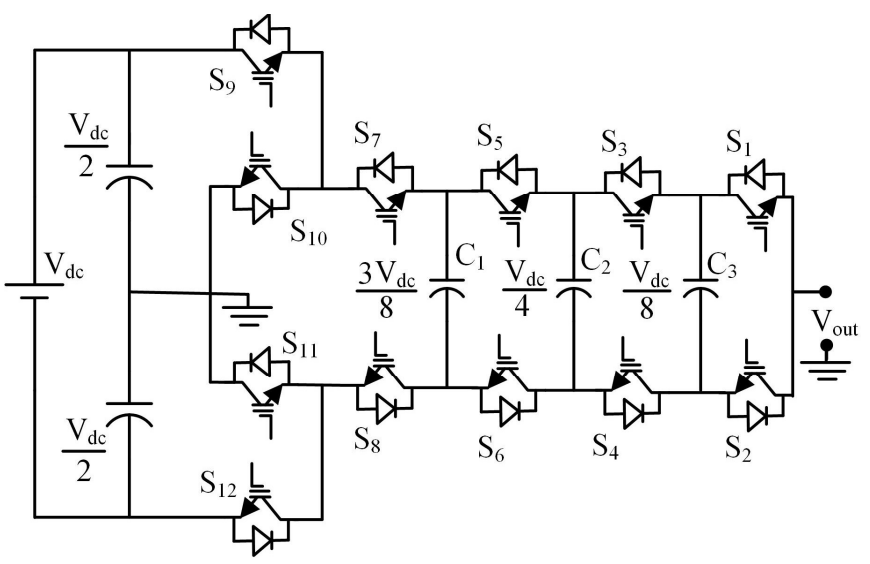

Fig. 1. Traditional 9-level single-phase ANPC.

Fig. 2. Proposed nine-level active neutral point inverter for distribution grid integration of solar photovoltaic power plants. 
One of the emerging multilevel inverter topologies is the ANPC multilevel inverter topology which was first introduced in 2005 [10]. This power converter can eliminate the problems with the previous neutral point clamp and the capacitor clamp multilevel inverters. Fig. 1 shows the single-phase 9-level ANPC inverter circuit. This ANPC multilevel inverter topology requires a smaller number of clamping devices than those in the neutral point clamp and the flying capacitor multilevel inverter topologies.

Using the ANPC multilevel inverter topology, a nine-level single-phase ANPC multilevel inverter topology requires $1 \mathrm{dc}$ power source, 2 dc-link capacitors, 12 switching devices and 3 flying capacitors to develop a single-phase nine-level inverter. The main problems with this topology are the voltage balancing issue of the flying capacitors and the issue of only having $50 \%$ utilization of the dc bus voltage.

\section{THE Proposed CONVERTER TOPOLOGY}

The proposed active nine-level neutral point clamp inverter topology is shown in Fig. 2. The single-phase unit uses $1 \mathrm{dc}$ power source, 10 switching devices, 2 dc-link capacitors and 1 flying capacitor. The main advantage of the proposed converter topology is that it requires a smaller number of electronic switches and flying capacitors compared to the traditional ANPC multilevel inverter topology. Further, the proposed power converter topology can also solve the voltage balancing issue of the flying capacitors by using the highfrequency magnetic link. Also, the proposed converter topology utilizes $100 \%$ of the dc bus voltage and the galvanic isolation can be obtained due to the use of the high-frequency transformer.

Here, the dc power from the PV array is converted into the high-frequency ac power using a full-bridge inverter. The high-frequency ac is then passed through the primary winding of the high-frequency magnetic link. The magnetic link produces the high-frequency ac in the 6 secondary windings. As the number of turns in the secondary windings is different from each other, the windings will produce ac voltages of different magnitudes. If the voltage across the $\mathrm{C}_{1}$ and $\mathrm{C}_{2}$ capacitor is $\mathrm{V}_{\mathrm{dc}}$, then the flying capacitor should maintain a voltage of $\mathrm{V}_{\mathrm{dc}} / 4$ across it.

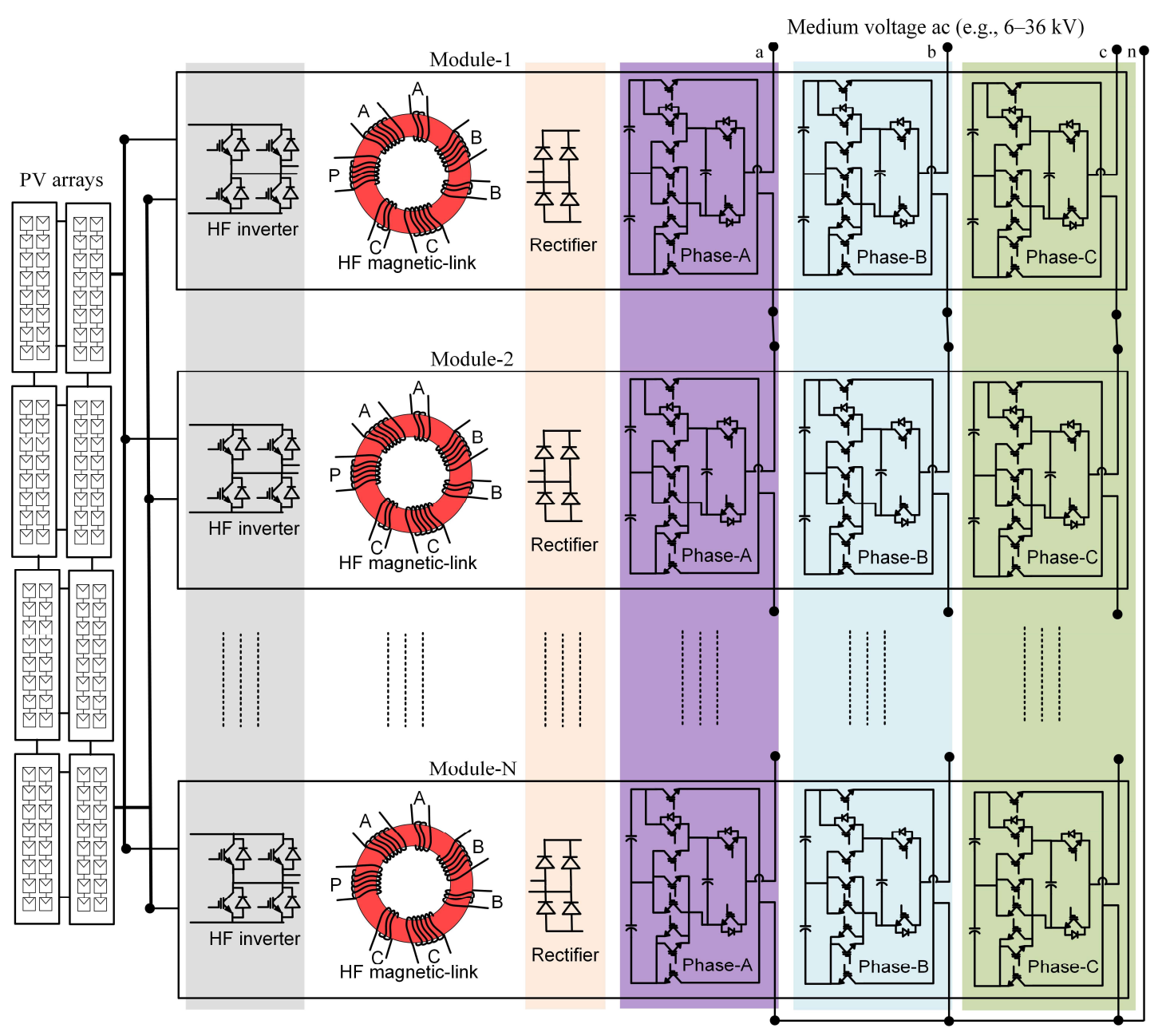

Fig. 3 The proposed power converter for medium voltage grid integration of PV array. 
Therefore, the number of turns in the secondary windings is different. The high-frequency ac from the secondary windings are passed through the rectifier circuit and then the obtained balanced dc power supplies are fed in the new active point clamp multilevel inverter which is then directly connected to the grid. The proposed magnetic link-based power converter is also suitable for grid integration without using a power frequency transformer. Here, the magnetic link will provide the isolation between the grid and the PV power plant.

However, the integration of solar energy with the medium voltage grid is possible by the parallel operation of the modules of the proposed power converter as presented in Fig. 3 . Each module contains a high-frequency inverter, a magnetic link, a rectifier circuit and an ANPC multilevel inverter. Here, the ANPC multilevel inverter of one module is cascaded with the ANPC multilevel inverter of the next module. This cascading results in using lower rating converters and magnetic link for each module. Therefore, the power handling capacity of the magnetic link would not be an issue for the multilevel inverter for the grid integration with medium voltage grid. Moreover, in this case, the system becomes more reliable as other modules can be in operation if one or more modules need to be isolated.

There are currently various several high capacity MVA level $\mathrm{HF}$ ac transformers in practical applications. For example, a 1.2-MVA HF ac transformer is currently in use by the Swiss Federal Railways [17]. Fig. 4 shows the amorphous ribbon ( $0.02 \mathrm{~mm}$ thick and $0.025 \mathrm{~m}$ wide), magnetic core. Due to the use of the advanced material in the core, the core produces low losses, which makes the power conversion system more efficient.

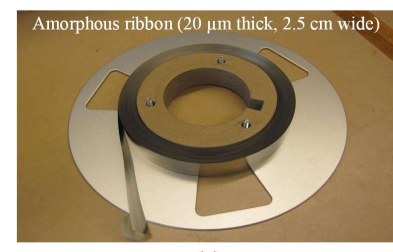

(a)

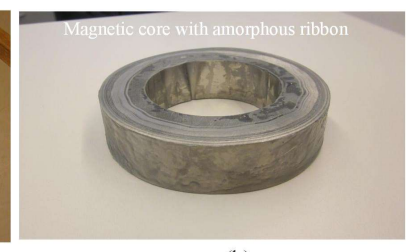

(b)
Fig. 4. (a) Amorphous ribbon, and (b) magnetic core under study.

TABLE I

SWITCHING TABLE

\begin{tabular}{llllllllllll}
\hline \hline \multirow{2}{*}{ State } & \multicolumn{10}{c}{ Switching states } & \multirow{2}{*}{$\mathrm{V}_{\text {out }}$} \\
\cline { 2 - 10 } & $\mathrm{S}_{1}$ & $\mathrm{~S}_{2}$ & $\mathrm{~S}_{3}$ & $\mathrm{~S}_{4}$ & $\mathrm{~S}_{5}$ & $\mathrm{~S}_{6}$ & $\mathrm{~S}_{7}$ & $\mathrm{~S}_{8}$ & $\mathrm{~S}_{9}$ & $\mathrm{~S}_{10}$ & \\
\hline 1 & 1 & 0 & 0 & 0 & 0 & 0 & 0 & 0 & 1 & 1 & $\mathrm{~V}_{\mathrm{dc}} / 4$ \\
\hline 2 & 1 & 0 & 0 & 0 & 1 & 0 & 0 & 0 & 0 & 1 & $\mathrm{~V}_{\mathrm{dc}} / 2$ \\
\hline 3 & 1 & 0 & 0 & 0 & 0 & 1 & 0 & 0 & 0 & 1 & $3 \mathrm{~V}_{\mathrm{dc}} / 4$ \\
\hline 4 & 1 & 0 & 0 & 1 & 0 & 0 & 0 & 0 & 0 & 1 & $\mathrm{~V}_{\mathrm{dc}}$ \\
\hline 5 & 0 & 1 & 1 & 0 & 0 & 0 & 0 & 0 & 0 & 0 & $-\mathrm{V}_{\mathrm{dc}} / 4$ \\
\hline 7 & 0 & 1 & 1 & 0 & 0 & 0 & 1 & 0 & 0 & 0 & $-\mathrm{V}_{\mathrm{dc}} / 2$ \\
\hline 9 & 1 & 0 & 1 & 0 & 0 & 0 & 0 & 1 & 0 & 0 & $-3 \mathrm{~V}_{\mathrm{dc}} / 4$ \\
\hline $9 \mathrm{a}$ & 1 & 0 & 1 & 0 & 0 & 0 & 0 & 0 & 0 & 0 & 0 \\
\hline \hline & 0 & 0 & 0 & 0 & 0 & 0 & 0 & 0 & 1 & 1 & 0 \\
\hline \hline
\end{tabular}

Table I and Fig. 5 depicts the different operating modes for the switching devices to obtain the different voltage levels.

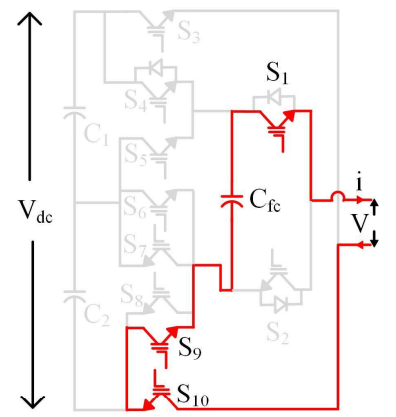

Level $1, \mathrm{~V}_{\mathrm{dc}} / 4$

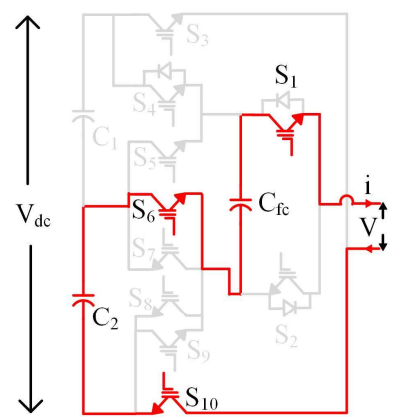

Level 3, $3 \mathrm{~V}_{\mathrm{dc}} / 4$

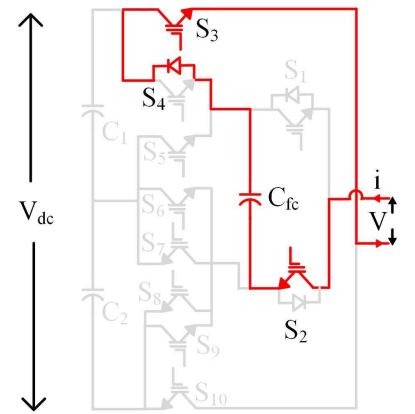

Level $5,-\mathrm{V}_{\mathrm{dc}} / 4$

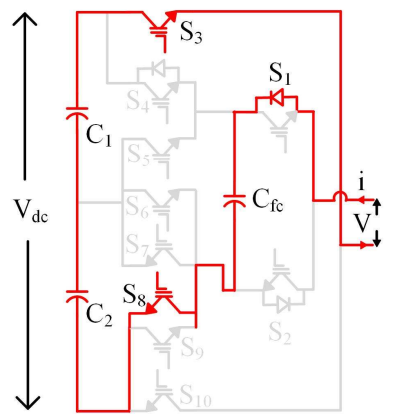

Level $7,-3 \mathrm{~V}_{\mathrm{dc}} / 4$

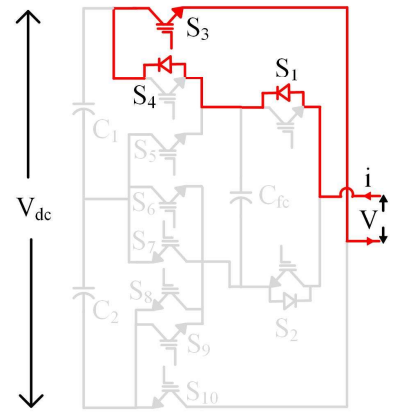

Level 9a, 0

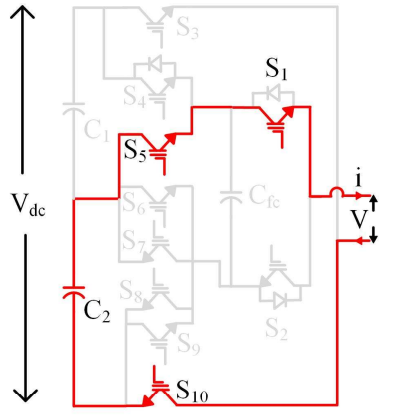

Level 2, $\mathrm{V}_{\mathrm{dc}} / 2$

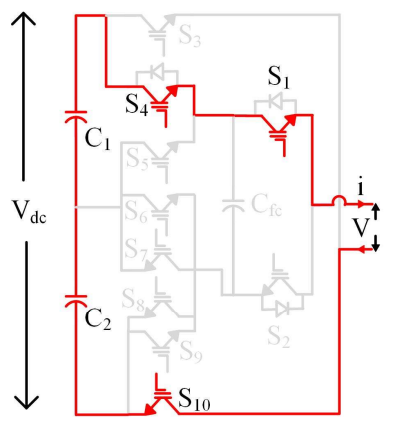

Level $4, \mathrm{~V}_{\mathrm{dc}}$

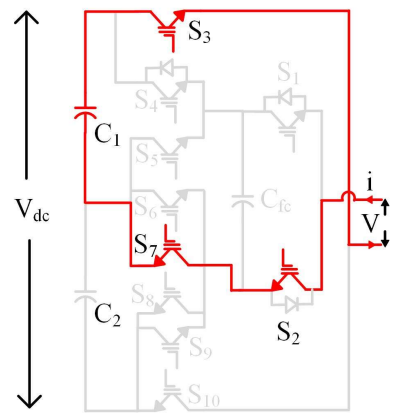

Level $6,-\mathrm{V}_{\mathrm{dc}} / 2$

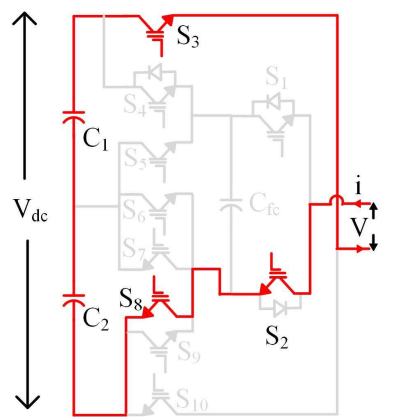

Level 8, $-\mathrm{V}_{\mathrm{dc}}$

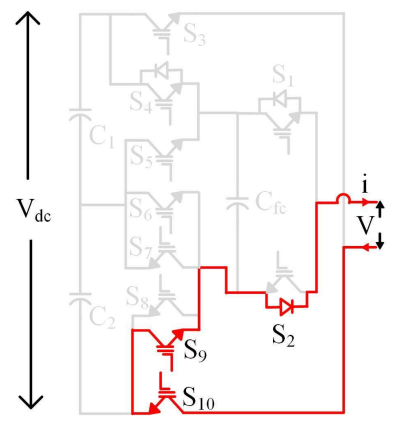

Level 9b, 0
Fig. 5. Different modes for the proposed multilevel inverter. 

follows

The voltage stresses across the electronic switches are as

$\mathrm{S}_{1} \rightarrow \mathrm{V}_{\mathrm{dc}} / 4, \quad \mathrm{~S}_{2} \rightarrow \mathrm{V}_{\mathrm{dc}} / 4, \quad \mathrm{~S}_{3} \rightarrow \mathrm{V}_{\mathrm{dc}}, \quad \mathrm{S}_{4} \rightarrow 3 \mathrm{~V}_{\mathrm{dc}} / 4, \quad \mathrm{~S}_{5} \rightarrow \mathrm{V}_{\mathrm{dc}} / 2$, $\mathrm{S}_{6} \rightarrow \mathrm{V}_{\mathrm{dc}} / 2, \mathrm{~S}_{7} \rightarrow \mathrm{V}_{\mathrm{dc}} / 2, \mathrm{~S}_{8} \rightarrow 3 \mathrm{~V}_{\mathrm{dc}} / 4, \mathrm{~S}_{9} \rightarrow 3 \mathrm{~V}_{\mathrm{dc}} / 4, \mathrm{~S}_{10} \rightarrow \mathrm{V}_{\mathrm{dc}}$.

\section{Model Predictive Control For the Proposed ANPC MULTILEVEL INVERTER}

The proposed ANPC multilevel inverter is connected to the grid through an L-type filter. Therefore, from the Kirchhoff's voltage law, the following expression can be derived.

$$
V_{i}=V_{g}+i_{L} R+L \frac{d i_{L}}{d t}
$$

where $V_{i}=\left[\begin{array}{ll}V_{i \alpha} & V_{i \beta}\end{array}\right]^{\mathrm{T}}$ is the inverter output voltage, $V_{g}=$ $\left[V_{g \alpha} V_{g \beta}\right]^{\mathrm{T}}$ is the grid voltage, $i_{L}=\left[i_{L \alpha} i_{L \beta}\right]^{\mathrm{T}}$ is the current through the filter inductor, $L$ is the inductance of the filter and $R$ is the resistance of the filter.

TABLE II

SWITCHING States AND FIRSt 16 TyPes of Voltage Vectors

\begin{tabular}{|c|c|c|}
\hline Switching State & Voltage Vector Magnitude & $\begin{array}{c}\text { Number } \\
\text { of } \\
\text { Vectors }\end{array}$ \\
\hline$(-0-0-0)$ & 0 & 1 \\
\hline $\begin{array}{l}(-1-0-0),(-0-0-1),(-0-1-0), \\
(-1-0-0),(-0-0-1),(-0-1-0)\end{array}$ & $(2 / 3 \times E) / 8$ & 6 \\
\hline $\begin{array}{l}(-1-1-1),(-1-1-1),(-1-1-1) \\
(-1-1-1),(-1-1-1),(1-1-1)\end{array}$ & $(2 / 3 \times E) / 8 \times 2$ & 6 \\
\hline $\begin{array}{l}(-1-0-1),(0-1-1),(-1-1-0) \\
(-1-0-1),(0-1-1),(1-1-0)\end{array}$ & $(2 / 3 \times E) / 8 \times \sqrt{3}$ & 6 \\
\hline $\begin{array}{l}(-2-1-1),(1-1-2),(-1-2-1), \\
(-2-1-1),(-1-1-2),(1-2-1)\end{array}$ & $(2 / 3 \times E) / 8 \times 3$ & 6 \\
\hline $\begin{array}{l}(-2-0-1),(0-1-2),(-1-2-0) \\
(-2-0-1),(0-1-2),(1-2-0), \\
(-1-0-2),(0-2-1),(-2-1-0) \\
(-1-0-2),(0-2-1),(2-1-0)\end{array}$ & $\begin{array}{c}(2 / 3 \times E) / 8 \times \\
\left(3-\cos \left(60^{\circ}\right)\right) / \cos \left(60^{\circ} / 3\right)\end{array}$ & 12 \\
\hline $\begin{array}{l}(-2-2-2),(2-2-2),(-2-2-2), \\
(-2-2-2),(-2-2-2),(2-2-2)\end{array}$ & $(2 / 3 \times E) / 8 \times 4$ & 6 \\
\hline $\begin{array}{l}(-2-0-2),(0-2-2),(-2-2-0) \\
(-2-0-2),(0-2-2),(2-2-0)\end{array}$ & $(2 / 3 \times E) / 8 \times 2 \sqrt{3}$ & 6 \\
\hline $\begin{array}{l}(-2-1-2),(1-2-2),(-2-2-1), \\
(-2-1-2),(-1-2-2),(2-2-1), \\
(-2-1-2),(-1-2-2),(-2-2-1), \\
(-2-1-2),(1-2-2),(2-2-1)\end{array}$ & $\begin{array}{c}(2 / 3 \times E) / 8 \times \\
\left(4-\cos \left(60^{\circ}\right)\right) / \cos \left(60^{\circ} / 4\right)\end{array}$ & 12 \\
\hline $\begin{array}{l}(-3-2-2),(-2-2-3),(-2-3-2), \\
(-3-2-2),(-2-2-3),(2-3-2)\end{array}$ & $(2 / 3 \times E) / 8 \times 5$ & 6 \\
\hline $\begin{array}{l}(-3-1-2),(1-2-3),(-2-3-1), \\
(-3-1-2),(-1-2-3),(2-3-1), \\
(-2-1-3),(-1-3-2),(-3-2-1), \\
(-2-1-3),(1-3-2),(3-2-1)\end{array}$ & $\begin{array}{c}(2 / 3 \times E) / 8 \times \\
\left(5-\cos \left(60^{\circ}\right)\right) / \cos \left(60^{\circ} / 5\right)\end{array}$ & 12 \\
\hline $\begin{array}{l}(-3-0-2),(0-2-3),(-2-3-0), \\
(-3-0-2),(0-2-3),(2-3-0), \\
(-2-0-3),(0-3-2),(-3-2-0), \\
(-2-0-3),(0-3-2),(3-2-0)\end{array}$ & $\begin{array}{c}(2 / 3 \times E) / 8 \times \\
\left(5-2 \cos \left(60^{\circ}\right)\right) / \cos \left(60^{\circ} / 5 \times 2\right)\end{array}$ & 12 \\
\hline $\begin{array}{l}(-3-3-3),(3-3-3),(-3-3-3) \\
(-3-3-3),(-3-3-3),(3-3-3)\end{array}$ & $(2 / 3 \times E) / 8 \times 6$ & 6 \\
\hline $\begin{array}{l}(-3-0-3),(0-3-3),(-3-3-0) \\
(-3-0-3),(0-3-3),(3-3-0)\end{array}$ & $(2 / 3 \times E) / 8 \times 3 \sqrt{3}$ & 6 \\
\hline $\begin{array}{l}(-3-2-3),(2-3-3),(-3-3-2) \\
(-3-2-3),(-2-3-3),(3-3-2) \\
(-3-2-3),(-2-3-3),(-3-3-2) \\
(-3-2-3),(2-3-3),(3-3-2)\end{array}$ & $\begin{array}{c}(2 / 3 \times E) / 8 \times \\
\left(6-\cos \left(60^{\circ}\right)\right) / \cos \left(60^{\circ} / 6\right)\end{array}$ & 12 \\
\hline $\begin{array}{l}(-3-1-3),(1-3-3),(-3-3-1), \\
(-3-1-3),(-1-3-3),(3-3-1), \\
(-3-1-3),(-1-3-3),(-3-3-1) \\
(-3-1-3),(1-3-3),(3-3-1)\end{array}$ & $\begin{array}{c}(2 / 3 \times E) / 8 \times \\
\left(6-2 \cos \left(60^{\circ}\right)\right) / \cos \left(60^{\circ} / 6 \times 2\right)\end{array}$ & 12 \\
\hline
\end{tabular}

If $T_{s}$ is the sampling time, then the rate of change of the filter current with respect to time can be expressed as follows

$$
\frac{d i_{L}}{d t}=\frac{i_{L}(k+1)-i_{L}(k)}{T_{s}}
$$

where $i_{L}(k+1)$ and $i_{L}(k)$ are the filter current at $k+1$ sample time and at $k$ sample time respectively. Therefore, if $k$ represents the current situation, then $k+1$ represents the predicted situation.

TABLE III

\begin{tabular}{|c|c|c|}
\hline Switching State & Voltage Vector Magnitude & $\begin{array}{l}\begin{array}{c}\text { Number } \\
\text { of } \\
\text { Vectors }\end{array} \\
\end{array}$ \\
\hline $\begin{array}{l}(-4-3-3),(3-3-4),(-3-4-3), \\
(-4-3-3),(-3-3-4),(3-4-3)\end{array}$ & $(2 / 3 \times E) / 8 \times 7$ & 6 \\
\hline $\begin{array}{l}(-4-2-3),(2-3-4),(-3-4-2), \\
(-4-2-3),(-2-3-4),(3-4-2), \\
(-3-2-4),(-2-4-3),(-4-3-2), \\
(-3-2-4),(2-4-3),(4-3-2)\end{array}$ & $\begin{array}{c}(2 / 3 \times E) / 8 \times \\
\left(7-\cos \left(60^{\circ}\right)\right) / \cos \left(60^{\circ} / 7\right)\end{array}$ & 12 \\
\hline $\begin{array}{l}(-4-1-3),(1-3-4),(-3-4-1), \\
(-4-1-3),(-1-3-4),(3-4-1), \\
(-3-1-4),(-1-4-3),(-4-3-1), \\
(-3-1-4),(1-4-3),(4-3-1)\end{array}$ & $\begin{array}{c}(2 / 3 \times E) / 8 \times \\
\left(7-2 \cos \left(60^{\circ}\right)\right) / \cos \left(60^{\circ} / 7 \times 2\right)\end{array}$ & 12 \\
\hline $\begin{array}{l}(-4-0-3),(0-3-4),(-3-4-0), \\
(-4-0-3),(0-3-4),(3-4-0), \\
(-3-0-4),(0-4-3),(-4-3-0), \\
(-3-0-4),(0-4-3),(4-3-0)\end{array}$ & $\begin{array}{c}(2 / 3 \times E) / 8 \times \\
\left(7-3 \cos \left(60^{\circ}\right)\right) / \cos \left(60^{\circ} / 7 \times 3\right)\end{array}$ & 12 \\
\hline $\begin{array}{l}(-4-4-4),(4-4-4),(-4-4-4), \\
(-4-4-4),(-4-4-4),(4-4-4)\end{array}$ & $(2 / 3 \times E) / 8 \times 8$ & 6 \\
\hline $\begin{array}{l}(-4-0-4),(0-4-4),(-4-4-0), \\
(-4-0-4),(0-4-4),(4-4-0)\end{array}$ & $(2 / 3 \times E) / 8 \times 4 \sqrt{3}$ & 6 \\
\hline $\begin{array}{l}(-4-3-4),(3-4-4),(-4-4-3), \\
(-4-3-4),(-3-4-4),(4-4-3), \\
(-4-3-4),(-3-4-4),(-4-4-3), \\
(-4-3-4),(3-4-4),(4-4-3)\end{array}$ & $\begin{array}{c}(2 / 3 \times E) / 8 \times \\
\left(8-\cos \left(60^{\circ}\right)\right) / \cos \left(60^{\circ} / 8\right)\end{array}$ & 12 \\
\hline $\begin{array}{l}(-4-2-4),(2-4-4),(-4-4-2), \\
(-4-2-4),(-2-4-4),(4-4-2), \\
(-4-2-4),(-2-4-4),(-4-4-2), \\
(-4-2-4),(2-4-4),(4-4-2)\end{array}$ & $\begin{array}{c}(2 / 3 \times E) / 8 \times \\
\left(8-2 \cos \left(60^{\circ}\right)\right) / \cos \left(60^{\circ} / 8 \times 2\right)\end{array}$ & 12 \\
\hline $\begin{array}{l}(-4-1-4),(1-4-4),(-4-4-1), \\
(-4-1-4),(-1-4-4),(4-4-1), \\
(-4-1-4),(-1-4-4),(-4-4-1), \\
(-4-1-4),(1-4-4),(4-4-1)\end{array}$ & $\begin{array}{c}(2 / 3 \times E) / 8 \times \\
\left(8-3 \cos \left(60^{\circ}\right)\right) / \cos \left(60^{\circ} / 8 \times 3\right)\end{array}$ & 12 \\
\hline
\end{tabular}

SWITCHING STATES AND LAST 9 TYPES OF VOLTAGE VeCtors

Based on (1) and (2), the current prediction can be expressed as follows.

$$
i_{L}(k+1)=\frac{T_{s}\left(V_{i}(k)-V_{g}(k)-i_{L}(k) R\right)}{L}+i_{L}(k)
$$

Assuming a constant grid voltage during the sample period, the predicted real power $P(k+1)$ and reactive power $Q(k+1)$ injected to the grid can be expressed as follows.

$$
\begin{aligned}
& P(k+1)=\frac{3}{2} \operatorname{Re}\left(V_{g} i_{L}^{*}\right)=\frac{3}{2}\left(V_{g \alpha} i_{L \alpha}+V_{g \beta} i_{L \beta}\right) \\
& Q(k+1)=\frac{3}{2} \operatorname{Im}\left(V_{g} i_{L}^{*}\right)=\frac{3}{2}\left(V_{g \beta} i_{L \alpha}-V_{g \alpha} i_{L \beta}\right)
\end{aligned}
$$

Therefore, at sample time $k$, the filter current or the injected grid current can be predicted from (3) for different inverter output voltage vector $V_{i}$ and from the predicted current, the injected real power and reactive power can be predicted from (4) and (5) for different inverter output voltage vector $V_{i}$. The voltage vector which causes a minimum value of the cost function will be selected for that sample period. The cost function is defined as follows. 


$$
J=\sqrt{\left(P_{r e f}-P(k+1)\right)^{2}+\left(Q_{r e f}-Q(k+1)\right)^{2}}
$$

The inverter output voltage vector $V_{i}$ can be expressed as follows:

$$
V_{i}=\frac{2}{3}\left(V_{i a}+a V_{i b}+a^{2} V_{i c}\right)=\left[\begin{array}{ll}
V_{i \alpha} & V_{i \beta}
\end{array}\right]^{T}
$$

Here, for a nine-level inverter, $9^{3}=729$ voltage vectors can be formed. From these 729 voltage vectors several are redundant, resulting in 217 different voltage vectors. Table II and Table III show the 217 vector values with corresponding switching states. Here, the switching state of (100) means the phase $\mathrm{A}$, phase $\mathrm{B}$ and phase $\mathrm{C}$ inverter output voltages are $\mathrm{Vdc} / 4,0$ and 0 , respectively. Moreover, the switching state of (-423) means phase $\mathrm{A}$, phase $\mathrm{B}$ and phase $\mathrm{C}$ inverter output voltages are $-4 \mathrm{Vdc} / 4,2 \mathrm{Vdc} / 4$ and $3 \mathrm{Vdc} / 4$, respectively. The rest of the switching states are self-explanatory. Here, $E$ is the peak value of the inverter line to line voltage. The maximum voltage vector value is $2 E / 3$ and the minimum voltage vector value is $(2 E / 3) / 8$.

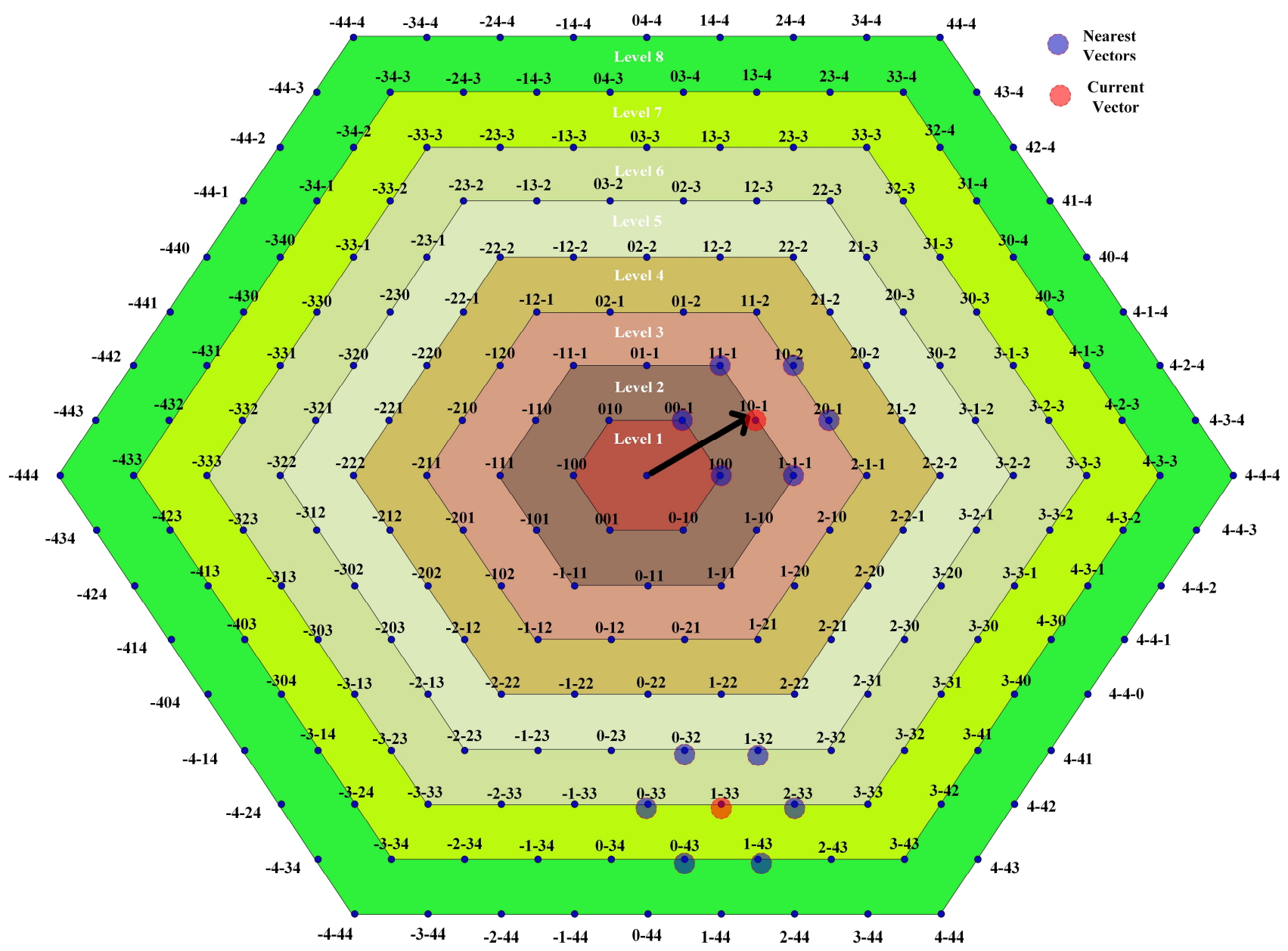

Fig. 6. Voltage vectors for the nine-level inverter.

Fig. 6 shows the possible voltage vectors for the nine-level inverter. Here, the computational burden is the same as a twolevel inverter. The reason is, all 217 vectors are not used for the prediction for a particular sample of time. The voltage vector is rotating in nature and the voltage is quite similar between two sample intervals. Therefore, only the adjacent vectors are taken into consideration. In Fig. 6, when the system operates at (10-1), then for the prediction of next sample, only seven vectors are taken into consideration and they are (10-1), (20-1), (10-2), (11-1), (00-1), (100) and (1-11). Similarly, if the system operates at $(1-33)$, then the adjacent vectors are (1-33), (2-33), (1-32), (0-32), (0-33), (0$43)$ and (1-43). The selection of the nearest vectors is done using an offline vector database. The database contains each vector and its nearest seven vectors. The distance between the vectors can be found from the following equation.

$$
d=\sqrt{\left(V_{i \alpha 1}-V_{i \alpha 2}\right)^{2}+\left(V_{i \beta 1}-V_{i \beta 2}\right)^{2}}
$$

where $d$ is the distance between two vectors.

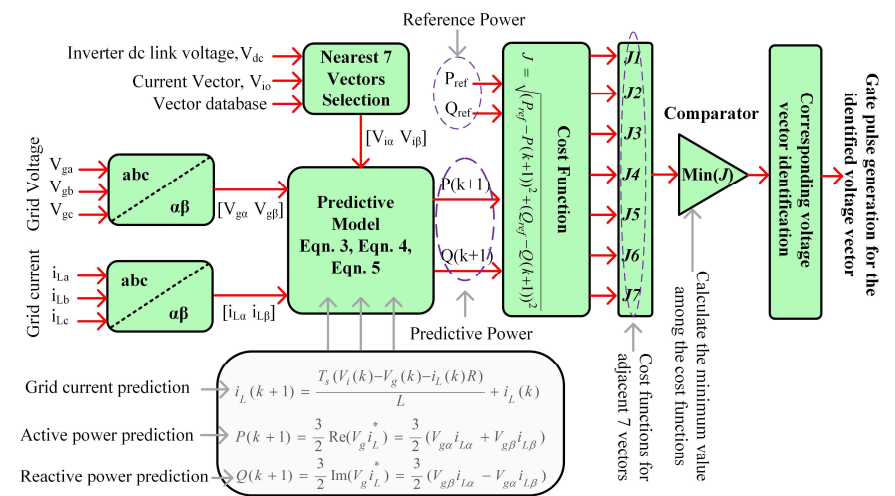

Fig. 7. Model predictive control for the proposed converter topology. 
Fig. 7 shows the model predictive control structure for the proposed power converter. Here, the three-phase grid voltage $\left(V_{g}\right)$ and the three-phase grid current or the filter inductor current $\left(i_{L}\right)$ are converted into alpha-beta components and fed into the predictive model block. Based on the current-voltage vector, seven adjacent vectors are selected and fed into the predictive model. The predictive model uses (3), (4) and (5) to calculate the predictive active and reactive power for the next sample. After that, these predicted values and reference values are used in the cost function and the corresponding switching of the voltage vector is selected based on which vector causes the minimum cost value among the adjacent seven vectors.

For simulation, a $1.5 \mathrm{~kW}$ PV system is connected with 230 $\mathrm{V}, 50 \mathrm{~Hz}$ grid system through the proposed power converter system. The inductance of filter, the resistance of filter, the capacitance of the dc-link capacitor, the capacitance of flying capacitors are taken as $1 \mathrm{mH}, 0.3 \Omega, 100 \mu \mathrm{F}$ and $100 \mu \mathrm{F}$, respectively. Fig. 8 shows the voltages across the dc-link capacitors and the flying capacitor for a phase. The voltage across the dc-link capacitors and the flying capacitors are found to be almost constant once the steady-state is reached.
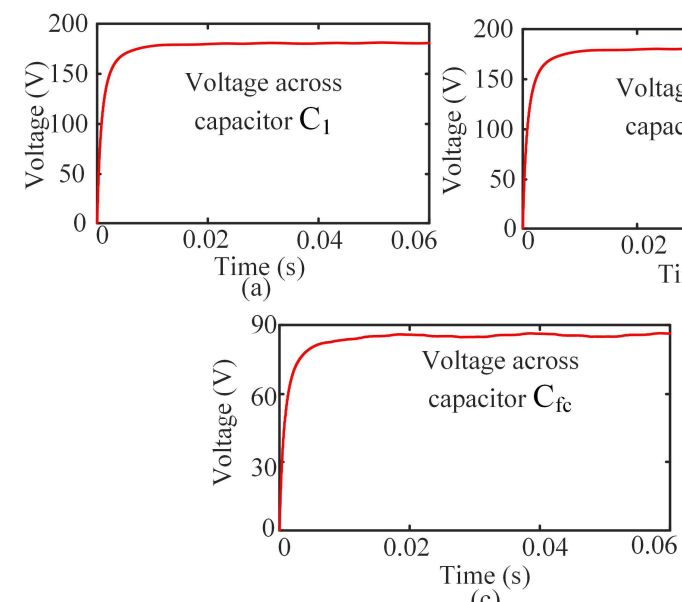

(c)

Fig. 8. Voltage waveform across (a) dc-link capacitor $\mathrm{C}_{1}$ (b) dc-link capacitor $\mathrm{C}_{2}$ (c) flying capacitor $\mathrm{C}_{\mathrm{fc}}$.

Fig. 9(a) and Fig. 9(c) show the output phase voltage and line voltage for the proposed nine-level active neutral point clamp inverter topology, respectively. Fig. 9(b) shows that the phase voltage has $13.99 \%$ total harmonic distortion. Fig. 9(d) shows that the total harmonic distortion of the line voltage is $8.53 \%$.

Fig. 10 shows the simulated system behaviour (the grid phase voltage and current) for a step change of active power reference. From $0 \mathrm{~s}$ to $0.2 \mathrm{~s}$, the active power reference is 1500 $\mathrm{W}$, from $0.2 \mathrm{~s}$ to $0.3 \mathrm{~s}$, the active power reference is $1000 \mathrm{~W}$ and from $0.3 \mathrm{~s}$ to $0.4 \mathrm{~s}$, the active power reference is again $1500 \mathrm{~W}$. The simulation results in Fig. 10 show that the grid voltage is unaffected, and the injected grid current follows the change in the active power reference. Fig. 10 also shows that the model predictive controller can adapt to the system instability and return quickly back to steady-state position. Here, the reactive power reference is maintained at zero, as the main purpose is to provide the active power from the PV to the grid.

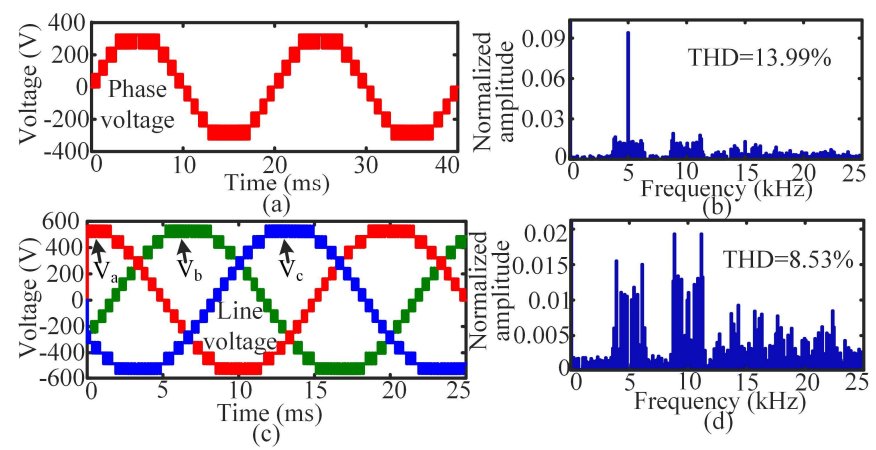

Fig. 9. Output phase voltage and line voltage with their spectra property for the proposed nine-level active neutral point clamp inverter topology.

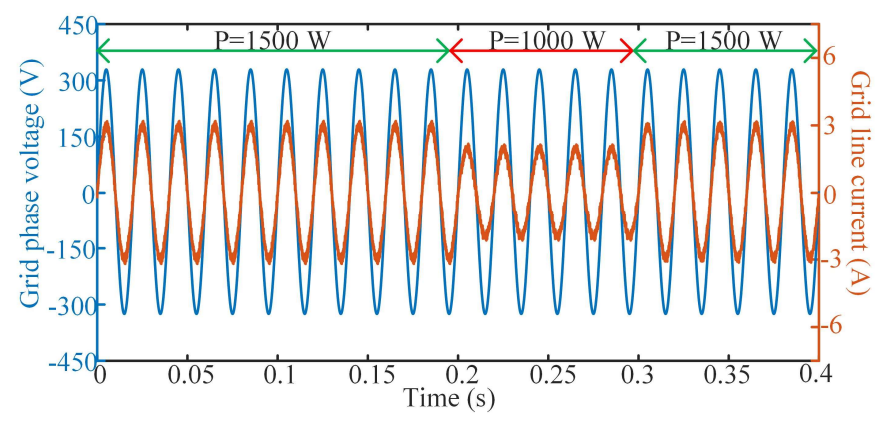

Fig. 10. Simulation system behaviour for a step change of active power (P).
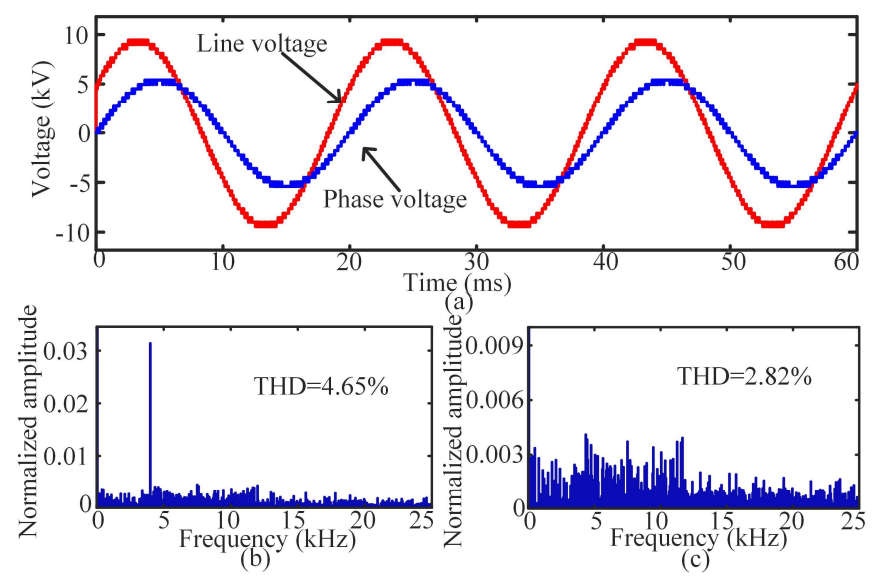

Fig. 11. Medium voltage grid integration of the proposed topology (a) phase and line voltage, (b) frequency spectrum of phase voltage and (c) frequency spectrum of line voltage.

Fig. 11 shows the simulated output voltages and their spectra property for the proposed topology and control when applied in a larger scale PV system for use in medium voltage grid. Here, considering the parallel operation of three modules of the proposed power converter, the output voltages and the corresponding frequency spectrum are presented. It is worth to mention that, each module can increase the voltage level by 8 . Therefore, by considering three modules of the proposed power converter, 25 voltage levels can be generated. The control of the 25 -level inverter can be designed similarly as explained in the beginning of Section IV. It is worth to mention that, the computational burden for the 25-level inverter would be the same as that of a two-level inverter (due 
to the need to consider only the nearest vectors for a particular sample time) as explained for 9 level inverter in the beginning of Section IV. Fig. 11(b) and 11(c) show that the THD of phase voltage is $4.65 \%$ and the THD of the line voltage is $2.82 \%$. Therefore, it is possible to remove the filter completely from the system.

\section{SWITCHING AND CONDUCTION LOSS ANALYSIS}

The main inverter losses are switching loss and conduction loss. An insulated-gate bipolar transistor (IGBT) consists of a switch and an anti-parallel diode. Due to the use of the modern fast recovery diodes, the diode turn-on loss is negligible. Therefore, in this paper, the switch turn-off loss $\left(P_{S L o f f}\right)$, the switch turn-on loss $\left(P_{S L o n}\right)$, the switch conduction loss $\left(P_{S C L}\right)$, the diode turn-off loss $\left(P_{r r L}\right)$ and the diode conduction loss $\left(P_{D C L}\right)$ are considered.

The switch conduction loss $\left(P_{s c l}\right)$ can be calculated using the values of the instantaneous voltage across the switch $\left(V_{c e}(t)\right)$ and the values of the instantaneous current through the switch $\left(i_{c}(t)\right)$ using (9). Similarly, the diode conduction loss $\left(P_{d c l}\right)$ can be calculated using the values of the instantaneous voltage across the diode $\left(v_{F}(t)\right)$ and the values of the instantaneous current through the diode $\left(i_{F}(t)\right)$ using (10).

$$
\begin{gathered}
P_{s c l}=\frac{1}{2 \pi} \int_{0}^{2 \pi}\left[v_{c e}(t) i_{c}(t)\right] d(w t) \\
P_{d c l}=\frac{1}{2 \pi} \int_{0}^{2 \pi}\left[v_{F}(t) i_{F}(t)\right] d(w t)
\end{gathered}
$$

For N number of switches, the switch conduction loss and the diode conduction loss can be expressed as follows.

$$
\begin{gathered}
P_{S C L}=\sum_{j=1}^{N} P_{s c l_{j}} \\
P_{D C L}=\sum_{j=1}^{N} P_{d c l_{j}}
\end{gathered}
$$

For switching loss analysis, the losses can be expressed as a function of the switch current from the corresponding switch datasheet [1]. The switch turn-on loss, the switch turn-off loss and the diode turn-off loss can be found from (13) - (15).

$$
\begin{gathered}
P_{\text {SLon }}=\frac{1}{T_{0}} \sum_{j=1}^{N} E_{\text {on }}\left(i_{c}\right) \\
P_{\text {SLoff }}=\frac{1}{T_{0}} \sum_{j=1}^{N} E_{\text {off }}\left(i_{c}\right)
\end{gathered}
$$

and

$$
P_{r r L}=\frac{1}{T_{0}} \sum_{j=1}^{N} E_{r e c}\left(i_{F}\right)
$$

Fig. 12 shows the switching loss distribution, the conduction loss distribution and the total loss distribution for the proposed nine-level active neutral point clamp multilevel inverter topology. For the switching loss distribution, the switch $\mathrm{S}_{3}$ shows the lowest switching loss and the switch $\mathrm{S}_{6}$ shows the highest switching loss among the electronic switches. On the other hand, the switches $\mathrm{S}_{9}$ and $\mathrm{S}_{1}$ show the lowest and highest conduction losses respectively. Finally, the switch $\mathrm{S}_{9}$ shows the lowest total loss and the switch $\mathrm{S}_{2}$ shows the highest total loss among the electronic switches. Here, the loss distribution analysis is carried out to design the rating of the heat sinks for the switching devices.

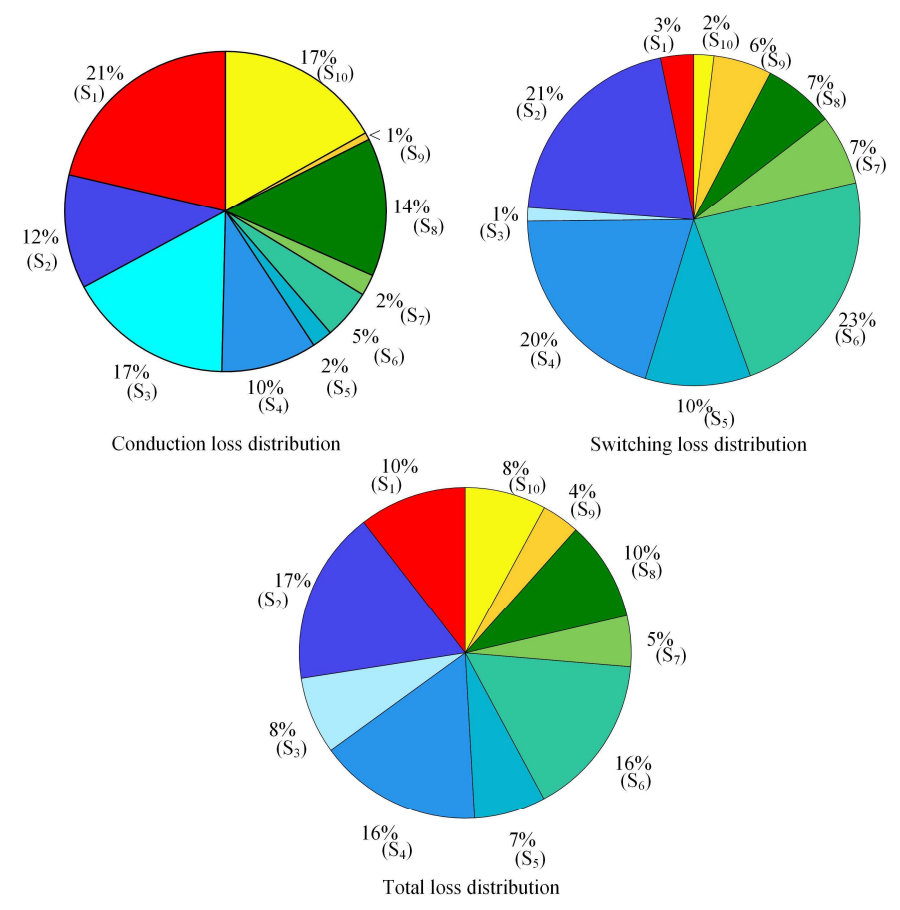

Fig. 12. Simulated (a) switching loss distribution (b) conduction loss distribution, and (c) total loss distribution.

\section{EXPERIMENTAL VALIDATION}

Fig. 13 shows the experimental setup and Fig. 14 shows the experimental results for the proposed model predictive control-based power converter topology. To validate the proposed nine-level active neutral point clamp inverter topology experimentally, the 43A, $1200 \mathrm{~V}$, HGTG11N120CND insulated gate bipolar transistor (IGBT) and the 15A, 350V, MJL4281A NPN bipolar transistor have been considered as the power electronic switches in the reduced scale prototype of the proposed energy conversion system.

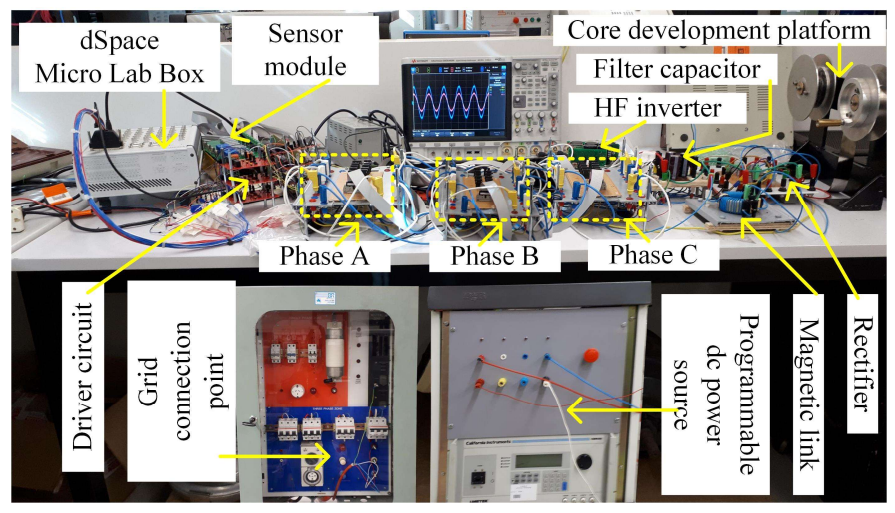

Fig. 13. Experimental test platform to validate the proposed nine-level active neutral point clamp inverter topology.

The ACPL-P343 driver circuit and the dSPACE MicroLabBox are used to implement the model predictive control of the proposed converter. The proposed converter is also tested in a micro-grid environment in the laboratory. The AMETEK CSW5550 programmable power supply is connected to the California Instruments MX45 (acting as the 
supply grid) to supply the developed nine-level active neutral point clamp inverter topology. The high-frequency magnetic link is implemented using advanced magnetic material and is used to eliminate the voltage unbalancing problem of the flying capacitors.

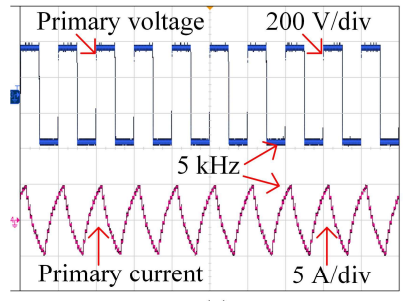

(a)

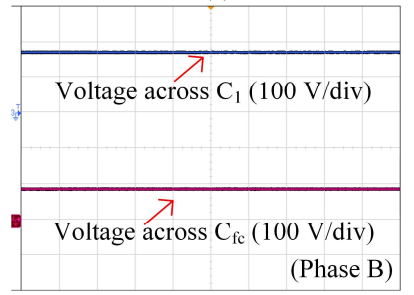

(c)

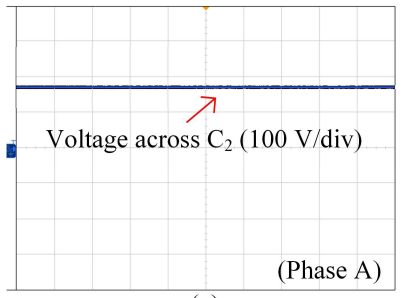

(e)

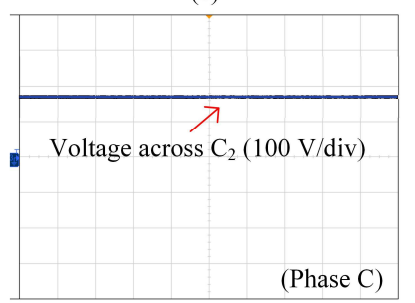

(g)

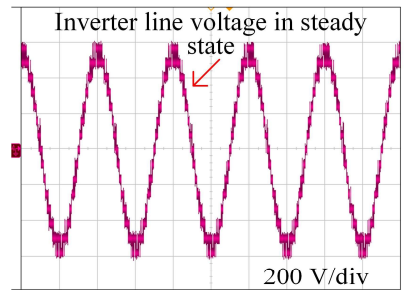

(i)

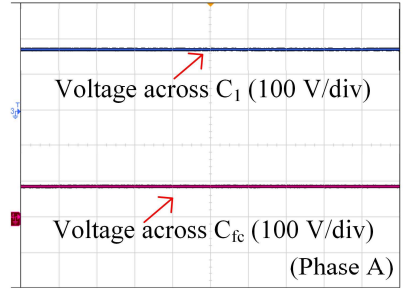

(b)

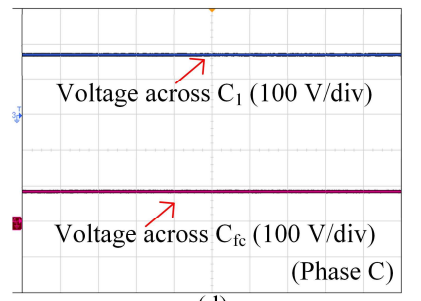

(d)

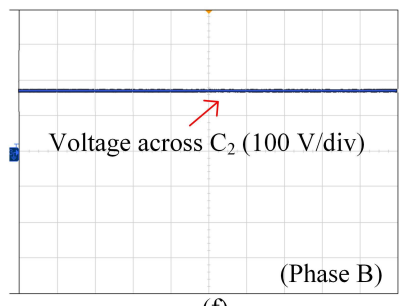

(f)

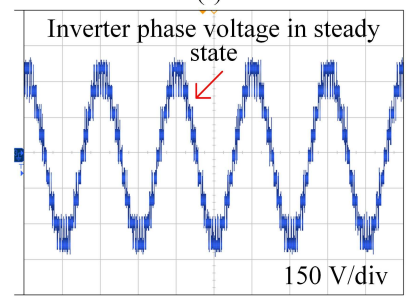

(h)

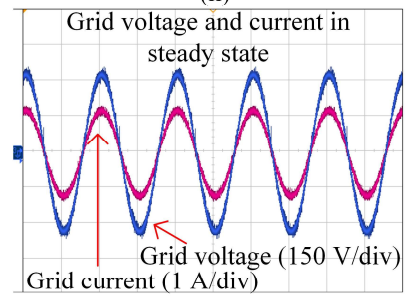

(j)
Fig. 14. (a) Primary voltage and current for the magnetic link, (b) voltage across capacitor $C_{1}$ and $C_{f c}$ for phase $A,(c)$ voltage across capacitor $C_{1}$ and $C_{f c}$ for phase $B,(d)$ voltage across capacitor $C_{1}$ and $C_{f c}$ for phase $C$, (e) voltage across capacitor $\mathrm{C}_{2}$ for phase $\mathrm{A}$, (f) voltage across capacitor $\mathrm{C}_{2}$ for phase $\mathrm{B},(\mathrm{g})$ voltage across capacitor $C_{2}$ for phase $C$, (h) inverter phase voltage in steadystate, (i) inverter line voltage in steady-state, and (j) grid voltage and current in steady-state.

Fig. 14(a) shows the high-frequency magnetic link primary voltage and current. Here, the high-frequency inverter generates a $5 \mathrm{kHz}$ square wave voltage, which is fed to the magnetic link. Figs. 14(b)-(d) show the dc-link capacitor $\left(\mathrm{C}_{1}\right)$ and the flying capacitor $\left(\mathrm{C}_{\mathrm{fc}}\right)$ voltages and Figs. 14(e)-(g) show the dc-link capacitor $\left(\mathrm{C}_{2}\right)$ voltages in different phases. The experimental results for the voltage waveforms across these capacitors in different phases prove that the magnetic link helps to generate and isolate the balanced dc power supplies from the grid-connected inverter. Figs. 14(h)-(i) show the steady-state inverter phase and line voltages respectively. From, the inverter phase and line voltage waveforms, it is obvious that the inverter can achieve nine different voltage levels. Fig. 14(j) shows the steady-state grid phase voltage and the grid phase current. Here, the input dc voltage and current are multiplied to calculate the input power. Also, the grid rms voltage and the injected rms current are multiplied and the output power is measured. By dividing the output power by the input power, the system efficiency is found to be $85 \%$. However, considering the ANPC inverter input power, the ANPC inverter efficiency is found to be $97 \%$. The power conversion system efficiency and the proposed inverter efficiency are also comparable to the traditional magnetic linked multilevel inverters, where for $100 \%$ loading, the system and the converter efficiency were found to be $76 \%$ and $95 \%$ respectively [18].

Fig. 15 shows the system response for a step-change in the active power reference. Fig. 15 also shows that the model predictive controller can manage the instability and return quickly back to the steady-state position.

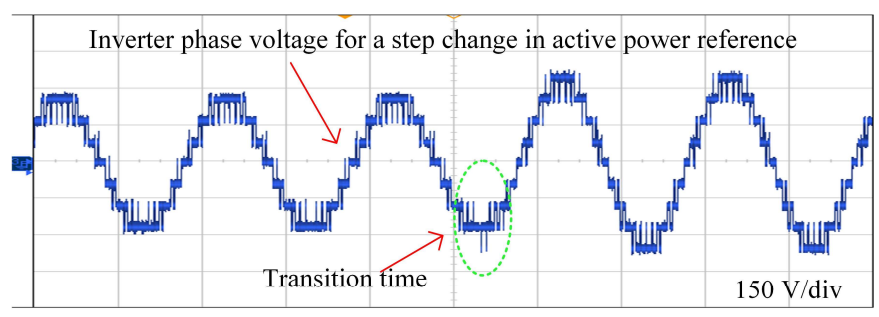

(a)

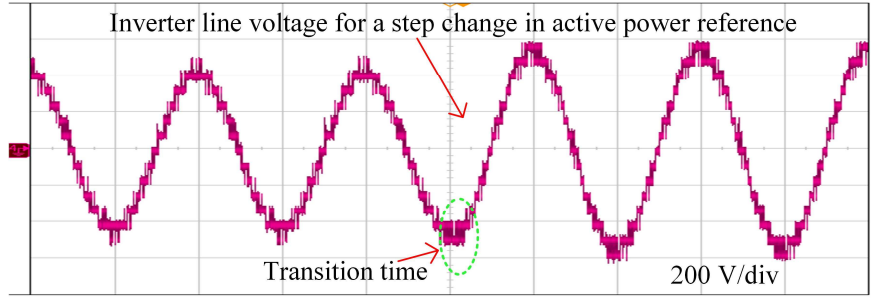

(b)

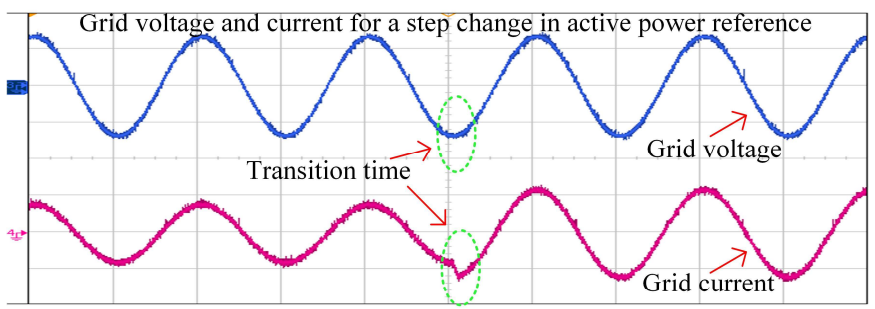

(c)

Fig. 15. System response for a step-change inactive power reference (a) inverter phase voltage, (b) inverter line voltage and (c) grid voltage and current.

\section{COMPARATIVE ASSESSMENT OF THE PROPOSED TOPOLOGY}

Table IV shows the comparison of the proposed nine-level active neutral point clamp inverter topology with the conventional multilevel inverter topologies, such as the traditional active neutral point clamp multilevel, the cascaded 
H-bridge multilevel, the capacitor clamped multilevel, the neutral point clamp multilevel, and some other improved active neutral point clamp inverter topologies [11]-[15] in terms of the number of circuit components. The proposed topology requires less number of circuit components and can be used to make the power conversion system more compact and efficient.

Table V illustrates the performance comparison of the proposed nine-level active neutral point clamp inverter topology with those from the conventional power converters. Here, the dc bus voltage utilization, the requirement of capacitor voltage control, the voltage balancing issue and the converter size are taken into consideration when comparing the performance of the proposed power converter topology. The proposed topology eliminates the extra control required for capacitor voltage, utilizes $100 \%$ dc bus voltage and does not have any issue with the voltage balancing.

TABLE IV

COMParison of Proposed MultileVel INVERTER TOPOlogy With Other Popular Nine LeVel Single Phase Inverters in TeRmS OF NumBer OF COMPONENTS

\begin{tabular}{|c|c|c|c|c|c|c|}
\hline \multirow[b]{2}{*}{ Multilevel Inverters } & \multicolumn{4}{|c|}{ Number of } & \multirow[b]{2}{*}{ 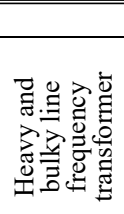 } & \multirow[b]{2}{*}{ 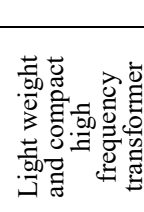 } \\
\hline & 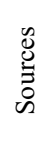 & 势 & 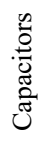 & $\begin{array}{l}\frac{\tilde{d}}{0} \\
\stackrel{0}{0}\end{array}$ & & \\
\hline
\end{tabular}

\begin{tabular}{|c|c|c|c|c|c|c|}
\hline Cascaded H-bridge[7] & 4 & 16 & - & - & 1 & 0 \\
\hline Diode clamped [7] & 1 & 16 & 8 & 14 & 1 & 0 \\
\hline Capacitor clamped [7] & 1 & 16 & 9 & - & 1 & 0 \\
\hline Traditional ANPC [10] & 1 & 12 & 5 & - & 1 & 0 \\
\hline $\begin{array}{c}\text { ANPC Proposed } \\
\text { in [11] }\end{array}$ & 1 & 12 & 4 & - & 1 & 0 \\
\hline $\begin{array}{l}\text { ANPC Proposed } \\
\text { in [12] }\end{array}$ & 1 & 12 & 4 & - & 1 & 0 \\
\hline $\begin{array}{c}\text { ANPC Proposed } \\
\text { in [13] }\end{array}$ & 2 & 16 & 6 & - & 1 & 0 \\
\hline $\begin{array}{c}\text { ANPC Proposed } \\
\text { in [14] }\end{array}$ & 1 & 10 & 3 & - & 1 & 0 \\
\hline Proposed ANPC & 1 & 10 & 3 & - & 0 & 1 \\
\hline
\end{tabular}

TABLE V

Performance Metrics of Different Nine Level Single Phase INVERTERS

\begin{tabular}{ccccc}
\hline \hline & \multicolumn{4}{c}{ Performance indicators } \\
\cline { 2 - 6 } Multilevel Inverters & $\begin{array}{c}100 \% \mathrm{dc} \\
\text { bus } \\
\text { utilization }\end{array}$ & $\begin{array}{c}\text { Requirement } \\
\text { of capacitor } \\
\text { voltage } \\
\text { control }\end{array}$ & $\begin{array}{c}\text { Voltage } \\
\text { balancing } \\
\text { problem }\end{array}$ & $\begin{array}{c}\text { Reduced } \\
\text { system } \\
\text { size }\end{array}$ \\
\hline Cascaded H-bridge[7] & $\sqrt{ }$ & $\times$ & $\sqrt{ }$ & $\times$ \\
\hline Diode clamped [7] & $\times$ & $\sqrt{ }$ & $\sqrt{ }$ & $\times$ \\
\hline Capacitor clamped [7] & $\times$ & $\sqrt{ }$ & $\sqrt{ }$ & $\times$ \\
\hline Traditional ANPC [10] & $\times$ & $\sqrt{ }$ & $\sqrt{ }$ \\
\hline ANPC Proposed in [11] & $\times$ & $\sqrt{ }$ & $\times$ \\
\hline ANPC Proposed in [12] & $\times$ & $\sqrt{ }$ & $\sqrt{ }$ \\
\hline ANPC Proposed in [13] & $\times$ & $\sqrt{ }$ & $\times$ \\
\hline ANPC Proposed in [14] & $\sqrt{ }$ & $\sqrt{ }$ & $\times$ \\
\hline Proposed ANPC & $\sqrt{ }$ & $\times$ & & $\sqrt{ }$ \\
\hline \hline
\end{tabular}

\section{CONCLUSION}

This paper presents model predictive control-based a new active neutral point clamp inverter topology for power frequency transformer-less grid integration of the photovoltaic power plants. The model predictive control technique can manage the system instability and return quickly back to the steady-state position. The proposed multilevel inverter can utilize $100 \%$ dc bus voltage and solves the voltage balancing issues faced by the traditional multilevel inverters. The proposed topology uses a smaller number of switching devices and flying capacitors and does not require additional control strategy for capacitor voltage balancing. The proposed power conversion system also offers galvanic isolation to the gridconnected photovoltaic systems, which is one of the most crucial issues for the power frequency transformer-less gridconnected photovoltaic systems. Therefore, the use of this proposed magnetic link-based power converter can make a photovoltaic power plant compact, efficient and reliable.

\section{REFERENCES}

[1] M. R. Islam, A. M. Mahfuz-Ur-Rahman, M. M. Islam, Y. G. Guo, and J. G. Zhu, "A modular medium voltage grid connected converter with improved switching techniques for solar photovoltaic systems," IEEE Trans. Ind. Electron., vol. 64, no. 11, pp. 8887-8896, Nov. 2017.

[2] A. M. Mahfuz-Ur-Rahman, M. R. Islam, K. M. Muttaqi and D. Sutanto, "An advance modulation technique for single-phase voltage source inverter to integrate SMES into low-voltage distribution," IEEE Trans. Appl. Supercond., vol. 29, no. 2, p. 5400305, Mar. 2019.

[3] F. Z. Peng, J. S. Lai, J. W. McKeever and J. VanCoevering, "A multilevel voltage-source inverter with separate dc sources for static VAR generation," IEEE Trans. Ind. Appl., vol. 32, no. 5, pp. 11301138, Sept./Oct. 1996.

[4] M. R. Islam, A. M. Mahfuz-Ur-Rahman, K. M. Muttaqi and D. Sutanto, "State-of-the-art of the medium-voltage power converter technologies for grid integration of solar photovoltaic power plants," IEEE Trans. Energy Conv., vol. 34, no. 1, pp. 372-384, Mar. 2019.

[5] A. M. Mahfuz-Ur-Rahman, M. R. Islam, K. M. Muttaqi and D. Sutanto, "A new magnetic linked active neutral point clamp converter for transformer-less direct grid integration of solar photovoltaic systems," In Proc. IEEE IAS Annu. Meeting, Baltimore, MD, USA, Sept. 29-Oct. 3, 2019, pp. 1-6

[6] A. M. Mahfuz-Ur-Rahman, M. R. Islam, K. M. Muttaqi and D. Sutanto, "A Magnetic-linked multilevel active neutral point clamped converter with an advanced switching technique for grid integration of solar photovoltaic systems," IEEE Trans. Ind. Appl., vol. 56, no. 2, pp. 19902000, Mar. 2020.

[7] L. G. Franquelo, J. Rodriguez, J. I. Leon, S. Kouro, R. Portillo and M. A. M. Prats, "The age of multilevel converters arrives," IEEE Ind. Electron. Mag., vol. 2, no. 2, pp. 28-39, Jun. 2008.

[8] G. Ding, G. Tang, Z. He, and M. Ding, "New technologies of voltage source converter (VSC) for HVDC transmission system based on VSC," in Proc. IEEE Power Energy Soc. Gen. Meeting, Pittsburgh, PA, USA, 2008, pp. 1-8.

[9] G. Gateau, T. A. Meynard, and H. Foch, "Stacked multicell converter (SMC): Properties and design," in Proc. IEEE 32nd Annu. Power Electron. Spec. Conf., Vancouver, BC, Canada, 2001, vol. 3, pp. 15831588.

[10] P. Barbosa, P. K. Steimer, L. Meysenc, J. Steinke, M. Winkelnkemper, and N. Celanovic, "Active neutral-point-clamped multilevel converters," in Proc. IEEE 36th Annu. Power Electron. Spec. Conf., Recife, Brazil, 2005, pp. 2296-2301

[11] T. Bruckner, S. Bernet, and H. Guldner, "The active NPC converter and its loss-balancing control," IEEE Trans. Ind. Electron., vol. 52, no. 3, pp. 855-868, Jun. 2005.

[12] K. Wang, Z. Zheng, D. Wei, B. Fan, and Y. Li, "Topology and capacitor voltage balancing control of a symmetrical hybrid nine-level inverter for high speed motor drives," IEEE Trans. Ind. Appl., vol. 53, no. 6, pp. 5563-5572, Nov.-Dec.2017.

[13] J. Li, S. Bhattacharya, and A. Q. Huang, "A new nine-level active NPC (ANPC) converter for grid connection of large wind turbines for distributed generation," IEEE Trans. Power Electron., vol. 26, no. 3, pp. 961-972, Mar. 2011.

[14] N. Sandeep and U. R. Yaragatti, "Operation and Control of a Nine-Level Modified ANPC Inverter Topology With Reduced Part Count for Grid- 
Connected Applications," IEEE Trans. Ind. Electron., vol. 65, no. 6, pp. 4810-4818, Jun. 2018.

[15] M. Abarzadeh, H. M. Kojabadi, and L. Chang, "A modified static ground power unit based on novel modular active neutral point clamped converter," IEEE Trans. Ind. Appl., vol. 52, no. 5, pp. 4243-4256, Sep./Oct. 2016

[16] H. R. Teymour, D. Sutanto, K. M. Muttaqi and P. Ciufo, "A novel modulation technique and a new balancing control strategy for a singlephase five-level ANPC converter," IEEE Trans. Ind. Appl., vol. 51, no. 2, pp. 1215-1227, Feb. 2015.

[17] D. Dujic, C. Zhao, A. Mester, J. K. Steinke, M. Weiss, S. L. Schmid, T. Chaudhuri, and P. Stefanutti, "Power electronic traction transformer low voltage prototype," IEEE Trans. Power Electron., vol. 28, no. 12, pp. 5522-5534, Dec. 2013.

[18] M. R. Islam, Y. G. Guo, and J. G. Zhu, "A high-frequency link multilevel cascaded medium-voltage converter for direct grid integration of renewable energy systems," IEEE Trans. Power Electron., vol. 29, no. 8, pp. 4167-4182, Aug. 2014.

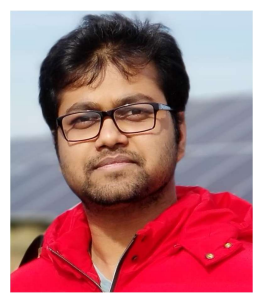

A. M. Mahfuz-Ur-Rahman (S'18) received the B.Sc. degree in Electrical and Electronic Engineering in 2016 from Rajshahi University of Engineering and Technology, Rajshahi, Bangladesh. He is currently working towards his $\mathrm{PhD}$ degree in the School of Electrical, Computer and Telecommunication Engineering, University of Wollongong, Australia. He is also recognized as a young talent researcher by the Australian department of home affairs through global talent independent program.

From Apr. 2017 to Feb. 2018, he served as a lecturer in the department of Electrical and Electronic Engineering at Bangladesh Army University of Science and Technology, Saidpur Cantonment, Nilphamari, Bangladesh. He has served as a reviewer for IEEE Transactions on Industrial Electronics, IEEE Transactions on Applied Superconductivity, and IEEE Access. His research interests include energy management system for microgrids, multilevel inverters, pulse width modulation techniques, protection of power devices, and grid integration of renewable energy resources mainly solar photovoltaic and wind.

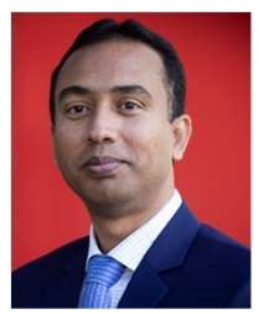

Md. Rabiul Islam received the Ph.D. degree from University of Technology Sydney (UTS), Sydney, Australia, in 2014 in electrical engineering.

He was appointed a lecturer at RUET in 2005 and promoted to full professor in 2017. In early 2018, he joined at the School of Electrical, Computer, and Telecommunications Engineering (SECTE), University of Wollongong (UOW), Wollongong, Australia. $\mathrm{He}$ is a Senior Member of IEEE. His research interests are in the fields of power electronic converters, renewable energy technologies, power quality, electrical machines, electric vehicles, and smart grid. He has authored or co-authored more than 170 papers including 48 IEEE Transactions/IEEE Journal papers. $\mathrm{He}$ has written or edited 4 technical books published by Springer. He has served as a Guest Editor for IEEE Transactions on Energy Conversion, IEEE Transactions on Applied superconductivity and IET Electric Power Applications. Currently he has been serving as an Editor for IEEE Transactions on Energy Conversion and IEEE Power Engineering Letters, and Associate Editor for IEEE Access. He has received several funding from Government and Industries including Australian Government ARC Discovery Project 2020 entitled "A Next Generation Smart Solid-State Transformer for Power Grid Applications"

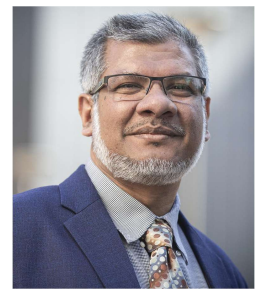

K M Muttaqi (M'01, SM'05) received the B.Sc. degree in electrical and electronic engineering from Bangladesh University of Engineering and Technology (BUET), Dhaka, Bangladesh in 1993, the M.Eng.Sc. degree in electrical engineering from University of Malaya, Kuala Lumpur, Malaysia in 1996 and the Ph.D. degree in Electrical Engineering from Multimedia University, Selangor, Malaysia in 2001. Currently, he is a Professor at the School of Electrical, Computer, and Telecommunications Engineering at the University of Wollongong, Wollongong, Australia. He was associated with the University of Tasmania, Hobart, Australia as a Research Fellow/Lecturer/Senior Lecturer from 2002 to 2007, and with the Queensland University of Technology, Brisbane, Australia as a Research Fellow from 2000 to 2002. Previously, he also worked for Multimedia University as a Lecturer for three years. He has more than 21 years of academic experience and authored or coauthored 285 papers in international journals and conference proceedings. His research interests include distributed generation, renewable energy, electrical vehicles, smart-grid, power system planning and emergency control.

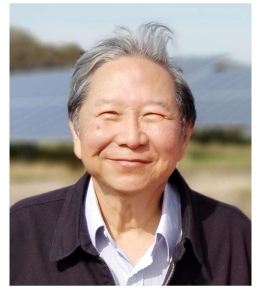

Danny Sutanto (SM'89) received the B.Eng. (Hons.) and $\mathrm{Ph} . \mathrm{D}$. degrees from the University of Western Australia, Perth, W.A., Australia, in 1978 and 1981, respectively. He is currently a Pro-fessor of power engineering with the University of Wollongong, Wollongong, N.S.W., Australia. His research interests include power system planning, power system emergency, analysis and harmonics, flexible alternating current transmission system, and battery energy storage systems. He was the IEEE Industry Applications Society Area Chair for Region 10 (Asia Pacific) from 2014 to 2017. 